\title{
Competitiveness of the travel and tourism industry in Latin America
}

\author{
Autores \\ Carmen Luisa Vásquez, Carlos Llorach
}

\begin{abstract}
Latin America is a prosperous and competitive region based on the activity of its travel and tourism. Globally, it is ranked third in competitiveness, after of Europe and Asia-Pacific, according to the publication of the WTTR 2019. This article shows an analysis of the competitiveness of their countries, using WTTE published from 2007 to 2019 by the WEF. For the first publication of these reports, 20 countries in the region were located, located in quartiles 2, 3 and 4 of the global position. For 2019, 21 countries are positioned, highlighting Mexico and Brazil in Quartile 1 worldwide. When making a detailed analysis of the subscripts scored in this last report, an important proximity is observed between New Zealand and Costa Rica in Conditions and policies in T\&T. When performing this same analysis of the pillars, Mexico ranks first globally and in the region in Natural Resources are Malta and Jamaica have the same score in T\&T Prioritization. It is shown that the region and its countries have managed to position themselves competitively worldwide.
\end{abstract}

Palabras clave:

Travel and tourism industry competitiveness index, World report travel and tourism competitiveness, Travel and tourism industry: Latin America 